\title{
Translocation of problem predators: is it an effective way to mitigate conflict between farmers and cheetahs Acinonyx jubatus in Botswana?
}

\author{
Lorraine K. Boast, Kyle Good and Rebecca Klein
}

\begin{abstract}
The translocation of predators believed to be preying on livestock is often perceived as a more humane and desirable method of removal than lethal control. However, the survival of translocated predators and the effectiveness of translocation in reducing conflict at the removal site are often not documented. We assessed farmers' perceptions of the efficacy of translocation at reducing livestock and gamestock losses in Botswana, and determined the post-release survival of translocated cheetahs Acinonyx jubatus, the most threatened large felid in Africa. Eighteen percent of translocated cheetahs survived 1 year $(n=11)$. The low survival rate was thought to be related to homing behaviour and wide-ranging movements post release. The majority of farmers who had translocated a problem predator from their farm within the 12 months prior to the study perceived that the translocation was ineffective at reducing stock losses, both in the short $(59.1 \%)$ and long term $(63.6 \%, n=22)$. At least one of the monitored cheetahs continued to predate livestock after release. In light of the low survival, significant financial costs and failure to reduce stock losses, we conclude that the translocation of problem cheetahs in Botswana should no longer be conducted, and that conflict mitigation methods should focus on techniques that promote coexistence of predators and humans.
\end{abstract}

Keywords Acinonyx jubatus, Botswana, cheetah, humanwildlife conflict, large felid, predator, translocation

To view supplementary material for this article, please visit http://dx.doi.org/10.1017/So030605315000241

\section{Introduction}

A increasing human population and the conversion of A land for anthropogenic activities have resulted in widespread conflict between humans and wildlife, and this is

Lorraine K. BoAst* (Corresponding author), Kyle Good and RebecCa Klein Cheetah Conservation Botswana, Private Bag BO 284, Bontleng Post Office, Gaborone, Botswana. E-mail lboast@yahoo.co.uk

*Also at: Animal Demography Unit, Department of Biological Sciences, University of Cape Town, Rondebosch 7701, Cape Town, South Africa

Received 26 October 2014. Revision requested 4 December 2014

Accepted 10 February 2015. First published online 20 May 2015. predicted to increase (Hutton \& Leader-Williams, 2003; Madden, 2004). Actual or perceived depredation of livestock by carnivores is the most common cause of conflict between humans and predators (Sillero-Zubiri \& Laurenson, 2001), and human intolerance and lethal removal of predators constitute one of the primary threats to the survival of nearly all large carnivore species (Woodroffe et al., 2005). The capture and translocation of problem individuals from the conflict site to another area within the species' range (IUCN, 1998) is thought to reduce livestock losses. Translocation is considered a humane method (Massei et al., 2010), and therefore conservation organizations may be under pressure to translocate problem individuals to prevent them being killed.

The majority of large carnivore species have been translocated to mitigate human-predator conflict (Linnell et al., 1997; Fontúrbel \& Simonetti, 2011), including the successful reintroduction and establishment of healthy populations of grey wolf Canis lupus, cheetah Acinonyx jubatus and lion Panthera leo (Bradley et al., 2005; Purchase et al., 2006; Hayward et al., 2007). However, high mortality rates, and incidences of homing behaviour and of reverting to livestock predation have also been reported (Linnell et al., 1997).

The reduction of conflict at the capture site should be considered the primary indicator of success for translocations to mitigate human-predator conflict but often the effect of translocations on conflict resolution is not documented (Linnell et al., 1997; Massei et al., 2010). Translocated individuals should have an acceptable chance of survival, defined by Fontúrbel \& Simonetti (2011) as surviving 1 year post release. Translocation should be costeffective relative to other available conflict mitigation methods (Massei et al., 2010); however, the costs of translocation are rarely reported (Fischer \& Lindenmayer, 2000). We discuss the success of a cheetah translocation programme in Botswana in the context of the aforementioned criteria. Questionnaire surveys were used to investigate farmers' perceptions of the efficacy of translocation at reducing stock losses to carnivore depredation, and this information was considered alongside information on the survival of translocated cheetahs. The cheetah is the most threatened large felid in Africa, and Botswana is geographically at the centre of the southern African cheetah population, the largest remaining population (IUCN/SSC, 2007). 


\section{Study area}

Botswana is a landlocked country in southern Africa $(581,730$ $\mathrm{km}^{2}$; Fig. 1), with mean temperatures of $35^{\circ} \mathrm{C}$ in summer and $1^{\circ} \mathrm{C}$ in winter, and annual rainfall of c. $200-600 \mathrm{~mm}$, during October-March (Central Statistics Office, 2013). The vegetation varies from scrub savannah and small trees in the drier south-west to tree savannah and woodland in the north-east, where there is more precipitation (Burgess, 2003).

Land use is divided into livestock/game-stock farmland, arable and pastoral land (58.2\%), wildlife management areas (22.1\%; designed primarily for wildlife conservation but also contain livestock), nationally protected parks and reserves (19.1\%), and city land and government ranches (o.6\%; Fig. 1; Central Statistics Office, 2013). Protected areas do not have predator-proof fencing (with the exception of the southwestern boundary of the Makgadikgadi National Park), and therefore movement of predators is largely unrestricted.

Questionnaire surveys of farmers were conducted primarily in the Central, Ghanzi, Ngamiland and NorthEast regional districts. Translocated problem cheetahs originated from the Ghanzi, Southern or Kgalagadi districts, in western Botswana, where a local conservation organization, Cheetah Conservation Botswana, has an active presence. Cheetahs were translocated to protected areas, wildlife management areas or farmland in this western region (Fig. 1).

\section{Methods}

\section{Questionnaires}

Questionnaires were administered as face-to-face interviews with game-stock and livestock farmers $(n=115$; refusal rate 12.1\%) during 2012-2013. Farmers were asked if they had ever translocated a predator from their property and, if so, how effective (very effective, effective, ineffective, very ineffective, do not know) they perceived the translocation had been at reducing stock losses to carnivore depredation in the short ( $\leq 3$ months) and long term ( $>3$ months). They were also asked how likely they would be to translocate a predator in the future (very likely, likely, unlikely, very unlikely, do not know) and to explain why. Any additional comments farmers made regarding predator translocations were recorded, as were details of the most recent translocation event. If a farmer was unable to remember the year the translocation took place it was assumed to have occurred $>12$ months prior to the survey.

All Department of Wildlife and National Parks offices in Botswana $(n=25)$ were contacted and asked to provide records of predator translocations conducted during 20102012, including the contact details of the farmers involved. These farmers were contacted by telephone and asked the same questions regarding predator translocations.

\section{Capture and translocation of cheetahs}

Cheetahs were captured during January 2003-May 2011, and a physical health check was carried out on adult individuals, as described in Houser et al. (2009) and Boast et al. (2013). The majority of cheetahs were caught by farmers using their own traps. Cheetahs were transported to Cheetah Conservation Botswana research bases and held for a median of 4 days before release (range o-16 days, $\mathrm{n}=21$ ).

Cheetahs were rated as being in excellent, good, fair or poor health; superficial trap-cage injuries were noted but were not considered in the assessment of health status (Marker \& Dickman, 2003). A global positioning system (GPS) cell collar (Africa Wildlife Tracking cc, Pretoria, South Africa; 450 g) or GPS satellite collar (Sirtrack Limited, Havelock North, New Zealand; $310 \mathrm{~g}$ ) was fitted to cheetahs during the physical health check. GPS locations were recorded 2-4 times per day, and visual follow-up was not conducted.

Release sites were selected through discussion between Department of Wildlife and National Parks and Cheetah Conservation Botswana staff at the time of capture; selections were based on vegetation, the availability of water and prey, the presence or absence of larger competitors (lion and spotted hyaena Crocuta crocuta), the cheetahs' social grouping, and the threat the cheetahs were thought to pose to livestock. Cheetahs were hard-released at the chosen site.

\section{Survival and post-release movements of translocated cheetahs}

Survival time of collared cheetahs was calculated as the number of days between their release (day o) and death or collar failure (day $\chi)$. The success rate was defined as the proportion of individuals that survived 1 year (Fontúrbel \& Simonetti, 2011). Spatial analyses were performed in ArcView GIS 3.2 (ESRI, Redlands, USA). Daily movements were monitored and, if applicable, the time taken for individuals to return to their capture site was recorded. A cheetah was considered to have returned to the capture site if a GPS location was recorded within $23.4 \mathrm{~km}$ of the site at which it was trapped. This is equivalent to the radius of the mean cheetah home range on farmland in Namibia, calculated based on 41 individuals (Marker et al., 2008). The Namibian home range was chosen because the home range calculated for Botswana (radius 11.4 $\mathrm{km}$; Houser et al., 2009) was based on a sample of only five individuals. Release-site fidelity was defined as an individual utilizing an area within $23.4 \mathrm{~km}$ of the release site more than once, $>60$ days after release.

\section{Statistical analyses}

Questionnaire data were coded for use in SPSS v. 11.o.1 (IBM Corporation, Armonk, USA). Statistical tests included the 


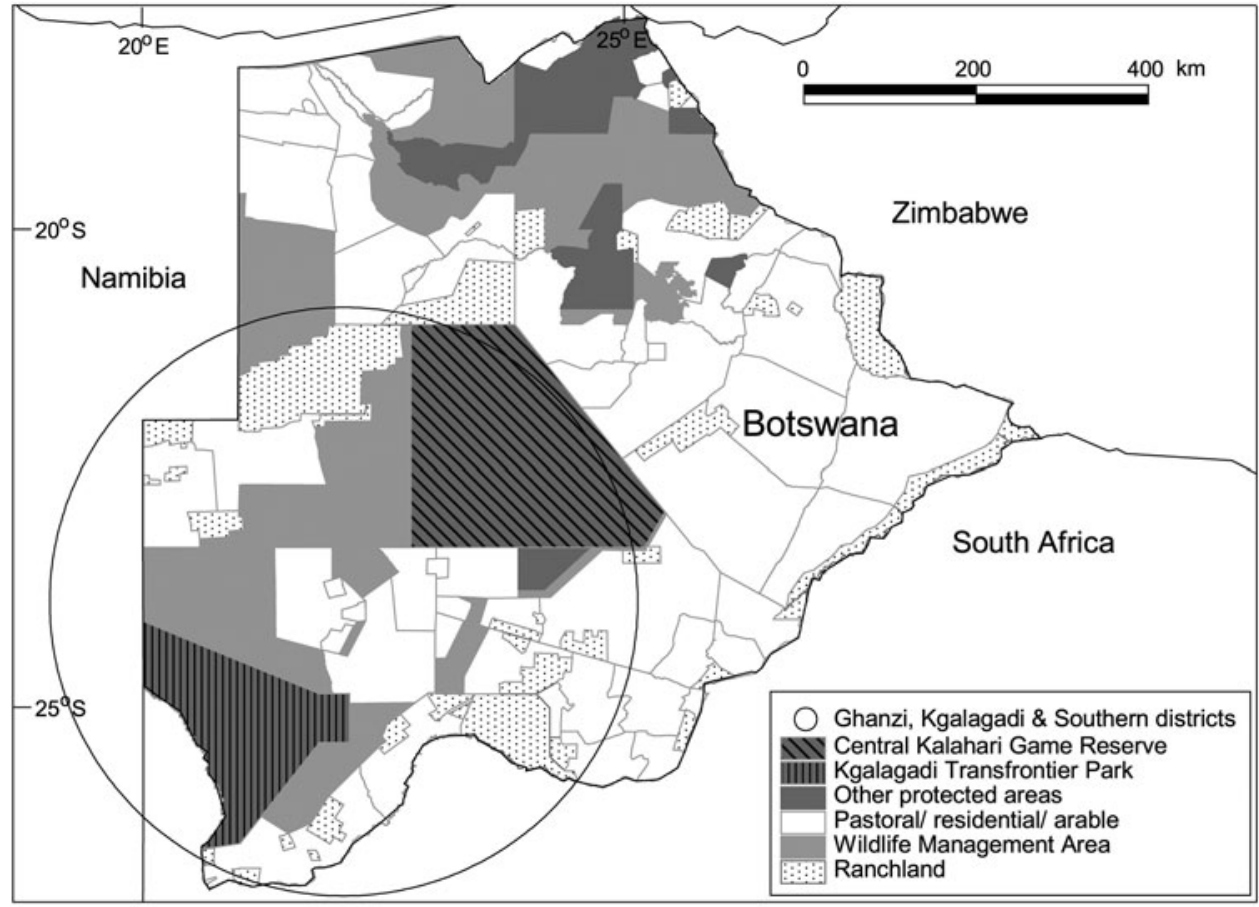

Fig. 1 Major land uses in Botswana. The circle indicates the location of the study area, where cheetahs Acinonyx jubatus were translocated by Cheetah Conservation Botswana. Data source: Department of Wildlife and National Parks (undated).
Mann-Whitney $U$ test, Wilcoxon signed-rank test and $\chi^{2}$ tests (using Yates's correction factor). Content analysis was used to identify consistent themes in the additional comments farmers made regarding translocation. Significance was determined at $\mathrm{P}=0.05$.

\section{Results}

\section{Questionnaires}

In the questionnaire survey $26.1 \%(\mathrm{n}=115)$ of farmers indicated they had been involved in the translocation of a problem predator. Predators were equally likely to have been translocated from ranches farming only game-stock ( $16.3 \%$ of ranches had translocated a predator, $n=43$ ), livestock farms $(29.6 \%, \mathrm{n}=27)$ or farms stocking both livestock and game-stock $\left(27.0 \%, \mathrm{n}=37 ; \chi^{2}=1.48, \mathrm{df}=2, \mathrm{P}=0.477\right)$. An additional 24 questionnaires were conducted with farmers identified from Department of Wildlife and National Parks records as having participated in translocation of a predator; in total, 54 people who had experience of translocations were questioned. The median time between translocation and interview was 2 years $(n=48$, range $0.25-28.00$ years); an additional six farmers could not remember the year the translocation took place. Farmers had translocated leopards Panthera pardus (55.5\%), lions (25.9\%), cheetahs (16.7\%), brown hyaenas Hyaena brunnea (9.3\%), black-backed jackals Canis mesomelas (1.9\%), African wild dogs Lycaon pictus $(1.9 \%)$ and spotted hyaenas (1.9\%).
Fifty-seven percent of farmers perceived that translocation was effective at reducing their stock losses in the short term $(57.1 \% ; n=49)$, compared to $46.9 \%(n=49)$ in the long term ( $U(48), z=-1.63, \mathrm{P}=0.102$; Table 1). Farmers' perceptions of efficacy did not vary with the species farmed, the reason for translocation or the species translocated. However, farmers who had translocated a predator within the 12 months prior to the study were up to 1.7 times less likely to rate the translocation as very effective or effective at reducing stock losses (short term: $40.9 \%$ of farmers; long term: $36.4 \% ; n=22$ ) than farmers who had translocated a predator $>12$ months prior to the study (short term: $70.4 \%, \mathrm{n}=27 ; U(49), z=-2.15$, $\mathrm{P}=0.032$; long term: $55.6 \%, \mathrm{n}=27 ; \quad U(49), z=-1.63$, $\mathrm{P}=0.104$; Table 1). Five farmers responded that they did not know how effective the translocation was.

Eighty-five percent $(84.6 \%)$ of farmers who had translocated a predator indicated they were very likely or likely to consider translocating predators in the future $(n=52)$, compared to $50.0 \%$ of farmers who had never been involved in predator translocation $\left(\mathrm{n}=80 ; \chi^{2}=18.85, \mathrm{df}=1, \mathrm{P}<0.001\right)$. Twenty percent $(20.2 \%)$ of farmers who commented on predator translocation did not want to translocate predators in the future, as they wanted to have predators on the farm $(\mathrm{n}=129$; Supplementary Table $\mathrm{S} 1$ ). Other reasons farmers stated as to why they would not translocate a predator in the future or why they thought translocation was ineffective were that predators are not moved far enough away (6.2\%), they return to the farm (16.3\%) or they do not survive after release $(12.4 \%)$. Farmers also reported that other predator species $(6.2 \%)$ or new individuals moved into the area 
TABLE 1 The proportion of farmers who perceived that the translocation of a predator had been effective or very effective at reducing stock losses on their farms in the short and long term.

\begin{tabular}{lll}
\hline & $\begin{array}{l}\text { \% farmers who perceived translocation had been effective or very } \\
\text { effective }(\mathrm{n})\end{array}$ & Long term \\
\cline { 2 - 3 } $\begin{array}{l}\text { Time interval since } \\
\text { predator was translocated }\end{array}$ & Short term & $36.4(22)$ \\
$\leq 12$ months & $40.9(22)$ & $55.6(27)$ \\
$>12$ months & $70.4(27)$ & $46.9(49)$ \\
Total & $57.1(49)$ & \\
\hline
\end{tabular}

TABLE 2 Estimated costs of translocating a cheetah Acinonyx jubatus from a farm $100 \mathrm{~km}$ from the research camp to a release site $250 \mathrm{~km}$ away by road. Staff costs were estimated at c. USD 300 for veterinary staff and USD 4.5 per hour for project staff, based on local wages.

\begin{tabular}{lr}
\hline Activity & Cost (USD)* \\
\hline Setting traps (travel \& staff) & 630 \\
Collection of cheetah (travel \& staff) & 100 \\
Medical work (veterinarian, equipment \& drugs) & 1,240 \\
Release of cheetah (travel \& staff) & 380 \\
Collection of traps (travel \& staff) & 420 \\
Monitoring (GPS satellite collar \& data retrieval) & 4,340 \\
Total & 7,110 \\
\hline
\end{tabular}

${ }^{*}$ Costs do not include initial material costs such as traps, holding pens, vehicles, squeeze boxes, and darting and medical equipment.

(4.7\%) and killed livestock or game-stock, and that in some cases stock losses to predators increased after translocation (3.9\%; Supplementary Table S1). Farmers were also concerned that there was nowhere to move the predators to because protected areas were unsuitable or at full capacity (7.8\%), and that the Department of Wildlife and National Parks and conservation NGOs were slow to respond and did not treat animals humanely (10.1\%) or were unwilling to assist in translocating predators $(7.8 \%)$.

\section{Translocation of cheetahs}

Cheetah Conservation Botswana took part in the translocation of 21 social groups of cheetahs (39 individuals) during 2003-2011. Male coalitions were the most commonly translocated group $(47.6 \%)$, followed by single males $(28.6 \%)$, females with cubs $(19.0 \%)$, and single females (4.8\%). Of the cheetahs that underwent a physical health check $88 \%$ $(n=26)$ were deemed to be in excellent or good health; the remaining cheetahs were in fair health. Minor to moderate trap-cage injuries, including abrasions to paws, face, shoulders, base of tail and hips, were recorded in $60 \%(\mathrm{n}=$ 25) of adults. The costs of translocation varied depending on how and where the cheetah was captured, the social grouping, veterinarian fees, the release point, and the follow-up conducted. The estimated cost to translocate a single problem cheetah was USD 7,110, $78.5 \%$ of which related to post-release monitoring and the physical health check (Table 2). The mean linear distance between capture and release sites was $138 \pm \operatorname{SD} 75 \mathrm{~km}(\mathrm{n}=21)$.
Survival and post-release movements of translocated cheetahs

GPS cell $(n=4)$ or satellite collars $(n=7)$ were fitted to 11 adult cheetahs. Median survival time was 106 days (range 46-981) for males and 31 days (range 21-95) for females (Table 3). Only two individuals survived for longer than 1 year, yielding a success rate of $18.2 \%(n=11)$; however, a third survived for 347 days (Table 3 ). Three of the four individuals whose release sites were $<50 \mathrm{~km}$ from their point of capture returned to the capture site, and one showed fidelity to the release site. Of the seven cheetahs translocated $>50$ $\mathrm{km}$ from the capture site, one returned to the capture area and one showed site fidelity to the release site (Table 3 ). A calf carcass and cheetah spoor were found at a location recorded from the GPS collar of a translocated male cheetah.

\section{Discussion}

Reduction of human-predator conflict at the capture site

Quantitative data on stock losses that occurred before and after predators were translocated were not available, and the few studies that have reported data have been conflicting and often inconclusive (Linnell et al., 1997). The drivers of human-predator conflict are often related to farmers' perceptions of predators and the threat and fear of economic losses rather than actual stock losses (Gusset et al., 2009), and therefore we considered farmers' attitudes to predator translocation 
TABLE 3 Data recorded for 11 collared cheetahs translocated as problem predators by Cheetah Conservation Botswana during 2003-2011, with identification number, health status, trap cage injuries, grouping/sex, release site, distance between capture and release site, release-site fidelity, return to capture site, duration of survival, outcome, and cause of death.

\begin{tabular}{|c|c|c|c|c|c|c|c|c|c|c|}
\hline $\begin{array}{l}\text { ID } \\
\text { no. }\end{array}$ & $\begin{array}{l}\text { Health } \\
\text { status }\end{array}$ & $\begin{array}{l}\text { Trap } \\
\text { cage } \\
\text { injuries }\end{array}$ & $\begin{array}{l}\text { Grouping/ } \\
\text { sex }\end{array}$ & $\begin{array}{l}\text { Release } \\
\text { site }^{1}\end{array}$ & $\begin{array}{l}\text { Distance } \\
\text { between } \\
\text { capture } \\
\text { \& release } \\
\text { sites }(\mathrm{km})\end{array}$ & $\begin{array}{l}\text { Release-site } \\
\text { fidelity }^{2}\end{array}$ & $\begin{array}{l}\text { Return to } \\
\text { capture } \\
\text { site }^{3}\end{array}$ & $\begin{array}{l}\text { Survival } \\
\text { (days) }\end{array}$ & Outcome & $\begin{array}{l}\text { Cause of } \\
\text { death }\end{array}$ \\
\hline$\overline{1}$ & Excellent & Yes & 1 male & Farmland & 48 & & Yes & 31 & Died & Shot \\
\hline 2 & Good & Yes & 1 male & Farmland & 28 & & Yes & 46 & Died & Unknown \\
\hline 3 & Good & Yes & 2 males $^{4}$ & Farmland & 29 & Yes & No & 145 & Died & Shot \\
\hline 4 & Good & Yes & 2 males $^{4}$ & Farmland & 31 & No & Yes & 64 & Died & Shot \\
\hline 5 & Good & No & 1 male & Farmland & 191 & No & No & 633 & Died & Unknown \\
\hline 6 & Fair & Yes & 1 male & CKGR & 215 & Yes & No & 66 & Died & Unknown \\
\hline 7 & Good & No & $\begin{array}{c}1 \text { female \& } \\
5 \text { cubs }\end{array}$ & CKGR & 200 & & No & 21 & Died & Unknown \\
\hline 8 & Good & Yes & 1 male & KTP & 79 & No & No & $>981$ & $\begin{array}{l}\text { Collar } \\
\text { failure }\end{array}$ & \\
\hline 9 & Good & Yes & $\begin{array}{c}1 \text { female \& } \\
3 \text { cubs }\end{array}$ & CKGR & 90 & & No & 31 & Died & Unknown \\
\hline 10 & Fair & Yes & $\begin{array}{l}1 \text { female \& } \\
2 \text { cubs }\end{array}$ & WMA & 278 & No & No & 95 & Died & Unknown \\
\hline 11 & Excellent & Yes & 2 males & KTP & 170 & No & Yes & 347 & Unknown & Unknown \\
\hline
\end{tabular}

${ }^{1}$ CKGR, Central Kalahari Game Reserve; KTP, Kgalagadi Transfrontier Park; WMA, Wildlife Management Area

${ }^{2}$ Defined as an individual utilizing an area within $23.4 \mathrm{~km}$ of the release site more than once $>60$ days after release

${ }^{3}$ Defined as a recorded GPS location within $23.4 \mathrm{~km}$ (radius of mean home range size; Marker et al., 2008) of the capture site

${ }^{4}$ Released separately

an appropriate measure to gauge its effectiveness at reducing stock losses and mitigating human-predator conflict.

Overall $57.1 \%$ of farmers perceived that translocation was effective at reducing stock losses in the short term; this decreased to $40.9 \%$ if farmers who had translocated a predator $>1$ year ago were excluded. Memories can be biased by what is known as rosy retrospection, in which individuals rate past events more positively than they would have rated them when the event occurred (Mitchell \& Thompson, 1994). It is possible this bias accounts for the observed differences, and therefore overall perceived effectiveness would probably have been lower if follow-up had been conducted nearer the time of translocation.

Farmers reported that translocation was ineffective, as other predators in the area or new predators that moved into the area continued to prey on livestock. The translocation of problem predators relies on the assumption that problem individuals (ones that repeatedly kill livestock) exist and can be identified and captured (Linnell et al., 1997; Linnell, 2011). If problem animals do not exist, however, or if the wrong individual is captured, livestock depredation is likely to continue. Additionally, the removal of territorial individuals has been associated with an increase in the number of subadult or transient individuals in an area (Phillips et al., 1991; Athreya, 2006), which could result in increased stock losses. Five farmers reported that their problems with predators increased after the translocation of a predator (Supplementary Table $\mathrm{S} 1$ ).

Farmers also commented that predation continues when translocated predators are not moved far enough away and are able to return to the capture site. Carnivores possess an intrinsic ability to navigate to their home area (Linnell et al., 1997); only two of the 11 collared cheetahs remained at the release site and four returned to their capture site. It is generally assumed that large carnivores are unlikely to return if they are moved $>100 \mathrm{~km}$ (Linnell et al., 1997). However, instances of long-distance homing such as that recorded for cheetah 11, which returned to its capture site from $170 \mathrm{~km}$ away (Table 3), have also been recorded for mountain lions Puma concolor, leopards, wolves and bears, and present a challenge when choosing release sites (Linnell et al., 1997; Weilenmann et al., 2010).

\section{Survival of translocated cheetahs}

Cheetahs have all the characteristics necessary for translocation: they consume a broad range of prey species, can tolerate a variety of habitats, and have an exploratory nature (Caro, 1994). However, cheetahs generally have lower survival rates than other translocated carnivores (Hayward et al., 2007); the post-release success rate of $18.2 \%$ reported 
here is substantially lower than that reported in a review of felid translocations (39 \pm SD 21\%; Fontúrbel \& Simonetti, 2011). The low survival rate in this study was likely to have been exacerbated by the hard-release of cheetahs into unfenced areas (Somers \& Gusset, 2009). Sixty-seven percent of cheetahs in this study and $47 \%$ of translocated felids in a review of predator translocations to mitigate human-predator conflict died within 110 days of release (Fontúrbel \& Simonetti, 2011). During the first 110 days, predators may be trying to return to the capture site or to establish themselves in the new area. Soft-release, where animals are held in a temporary holding enclosure at the release site to acclimatize them to the area before their release, can reduce post-release movements (Linnell et al., 1997) and has been associated with increased survival rates (Massei et al., 2010). A higher success rate was recorded in the soft-release of cheetahs into Matusadona National Park (36.0\%; Purchase \& Vhurumuku, 2005) compared to this study (18.2\%). Soft-release of cheetahs into private reserves with predator-proof fencing in South Africa has also had a high success rate ( $83 \%$; Marnewick et al., 2009); this can be attributed to the increased availability of post-release monitoring and veterinary treatment during the initial 110 days, and to the predators' inability to leave the relative safety of the reserve. Soft-release programmes are expensive, however, and despite the potential survival benefits of soft-release most predator translocation programmes are based on hard-release (Linnell et al., 1997; Fontúrbel \& Simonetti, 2011).

The availability of food and shelter, and a low presence of competitors, including humans, are thought to be the most important factors determining the survival of translocated animals (Fischer \& Lindenmayer, 2000; Johnson et al., 2010; Massei et al., 2010). In this study three of nine cheetahs that were confirmed dead were shot on farmland, and human-related causes were suspected in three other cases; human-mediated death is reported as the overall leading cause of mortality in predator translocations (Linnell et al., 1997; Massei et al., 2010; Fontúrbel \& Simonetti, 2011). The cause of death could not be confirmed in the other cases because of the lack of visual follow-up and the time delay in reaching the dead cheetahs, which is a common problem when animals are released into unfenced areas (Wolf et al., 1996). The poor survival of the three cheetahs released into the Central Kalahari Game Reserve (21-66 days; Table 3) may have been related to the high density of lions at the release sites, as lions have been largely extirpated from the capture sites (Winterbach, 2008). Pre-release exposure to predators has been shown to increase survival of translocated individuals (Griffin et al., 2000), and the naivety of the translocated cheetahs regarding lions may have contributed to their low survival rate (Bissett \& Bernard, 2007; Hayward et al., 2007; Marnewick et al., 2009).

Intraspecific competition has also been recorded as a cause of death in the translocation of cheetahs to electric- fenced game ranches in South Africa (Hofmeyr \& Van Dyk, 1998; Bissett \& Bernard, 2007), and between wild territorial males in the Serengeti (Caro, 1994). Cheetahs are widely distributed across Botswana and it is likely that resident cheetahs were present at the majority of release sites (Klein, 2007). Intraspecific competition is generally thought to be more detrimental to the translocated individual than to residents (Massei et al., 2010). The introduction of translocated predators could potentially endanger resident predator populations through disease exposure, genetic outbreeding and infanticide (Wolf et al., 1996); however, in this study the risks to resident cheetah populations were thought to be minimal because cheetahs are not thought to commit infanticide (Hunter \& Skinner, 2003), cheetah populations in Botswana are genetically similar (Dalton et al., 2013), and translocated cheetahs were screened for disease (Cheetah Conservation Botswana, unpubl. data). However, the translocation of species that commit infanticide, such as lions and leopards, which are reportedly the most commonly translocated species in Botswana, could result in territorial disputes, causing disruption to lion and leopard populations over a wide area (Treves \& Karanth, 2003; Balme et al., 2009; Kerth et al., 2013). Further study is needed to investigate the impact of repeated translocation of these species into Botswana's protected areas.

\section{Avoidance of human-predator conflict at release site}

Follow-up data on conflict at the release sites were not collected systematically but we know at least one individual continued to prey on livestock. The introduction of cheetahs into Matusadona National Park did not result in increased conflict between people and cheetahs at the Park's borders (Purchase \& Vhurumuku, 2005). However, other studies have shown that stock-raiding lions in sub-Saharan Africa and leopards in India continued killing livestock (and in the case of leopards, attacking people) after translocation (Funston, 2001; Frank et al., 2006; Athreya et al., 2011), and $25 \%$ of translocated wolves and $40 \%$ of brown bears Ursus arctos continued to prey on livestock or were involved in a conflict event within 2 years of release (Blanchard \& Knight, 1995; Bradley et al., 2005).

To reduce the potential for predators to continue to prey on livestock following translocation, the Department of Wildlife and National Parks releases them into protected areas (i.e. away from livestock). Protected areas in Botswana are unfenced, however, and as seen in this and other studies few translocated predators remain at their release site (Linnell et al., 1997; Weilenmann et al., 2010). The policy of translocating predators into protected areas could therefore be increasing human-predator conflict on farms bordering national parks and reserves. 


\section{Cost-effectiveness of cheetah translocations}

The cost of capturing, translocating and monitoring a single cheetah in this study was estimated to be USD 7,110, an amount that could compensate for at least 12 head of livestock (Fontúrbel \& Simonetti, 2011). In addition to financial costs, translocation draws on the limited resources of conservation organizations and state wildlife departments, diverting personnel and equipment away from other conflict mitigation activities.

\section{Conclusion}

To justify the economic cost of translocating problem predators the method must be more successful than other mitigation techniques (Massei et al., 2010). In this study, however, survival rates of translocated cheetahs were low, and stock losses continued at the capture site and potentially at the release site. Many farmers had a negative perception of translocation in terms of predator survival, the efficiency of the organizations involved or the efficacy of the method in reducing stock losses but they believed it gave the predator a chance of survival, compared to the alternative of lethal control, and $84.6 \%$ of farmers who had previously translocated a predator stated that they would probably do so again. The choice between lethal control and translocation is a dilemma for conservation organizations and potentially explains why many translocation programmes continue despite a low success rate (Athreya et al., 2011). Translocation programmes may provide farmers with an opportunity to obtain help if they can no longer tolerate a predator (Marnewick et al., 2009), and the availability of a coping strategy and perceived control over a risk reduces the perception of the magnitude of the threat (Dickman, 2008), which could result in increased tolerance of predators. It is difficult to ascertain if this potential benefit justifies the costs.

Our results concur with the conclusion of Linnell et al. (1997) that for carnivore species such as cheetahs in Botswana, where populations rather than individuals are the management units, translocation is unlikely to be justified and the money and time would be better spent on alternative mitigation methods such as compensation for loss of livestock, education programmes or improving farm management (Linnell et al., 1997; Massei et al., 2010; Fontúrbel \& Simonetti, 2011). The proactive prevention of humanpredator conflict is likely to be more effective than the reactive use of translocation as a temporary solution.

\section{Acknowledgements}

This study was conducted by Cheetah Conservation Botswana. The Ghanzi farming community and the Botswana Department of Wildlife and National Parks assisted with field work. The study was funded by the Howard Buffet Foundation, Wildlife Conservation Network and Stichting Spots, and the questionnaires were conducted in conjunction with research sponsored by National Geographic's Big Cats Initiative, Chester Zoo, the Comanis Foundation, the Prince Bernhard Fund for Nature, the Rufford Small Grants Foundation and Wilderness Wildlife Trust.

\section{References}

AthreyA, V. (2006) Is relocation a viable management option for unwanted animals? The case of the leopard in India. Conservation and Society, 4, 419-423.

Athreya, V., Odden, M., Linnell, J.D.C. \& Karanth, K.U. (2011) Translocation as a tool for mitigating conflict with leopards in humandominated landscapes of India. Conservation Biology, 25, 133-141.

Balme, G.A., Slotow, R. \& Hunter, L.T.B. (2009) Impact of conservation interventions on the dynamics and persistence of a persecuted leopard (Panthera pardus) population. Biological Conservation, 142, 2681-2690.

Bissett, C. \& Bernard, R.T.F. (2007) Habitat selection and feeding ecology of the cheetah (Acinonyx jubatus) in thicket vegetation: is the cheetah a savanna specialist? Journal of Zoology, 271, 310-317.

BlanChard, B.M. \& KNIGHT, R.R. (1995) Biological consequences of relocating grizzly bears in the Yellowstone ecosystem. The Journal of Wildlife Management, 59, 560-565.

Boast, L.K., Houser, A.M., Good, K.M. \& Gusset, M. (2013) Regional variation in body size of the cheetah (Acinonyx jubatus). Journal of Mammalogy, 94, 1293-1297.

Bradley, E.H., Pletscher, D.H., Bangs, E.E., Krunkel, K.E., SMITH, D.W., MACK, C.M. et al. (2005) Evaluating wolf translocation as a non-lethal method to reduce livestock conflicts in the north-western United States. Conservation Biology, 19, 1498-1508.

Burgess, J. (2003) Botswana forage resource profile. Http://www.fao. org/ag/AGP/AGPC/doc/Counprof/Botswana/botswana.htm [accessed 1 December 2013].

Caro, T.M. (1994) Cheetahs of the Serengeti Plains: Group Living in an Asocial Species. The University of Chicago Press, Chicago, USA.

Central Statistics Office (2013) Botswana Environment Statistics, 2012. Statistics Botswana, Gaborone, Botswana.

Dalton, D.L., Charruau, P., Boast, L. \& Kotze, A. (2013) Social and genetic population structure of free-ranging cheetah in Botswana; implications for conservation. European Journal of Wildlife Research, 59, 281-285.

Department of Wildlife and National Parks (n.d.) Botswana Global Information Systems Data. Department of Wildlife and National Parks, Gaborone, Botswana.

DiCKMAN, A.J. (2008) Key determinants of conflict between people and wildlife, particularly large carnivores, around Ruaha National Park, Tanzania. PhD thesis. University College London, London, UK.

Fischer, J. \& Lindenmayer, D.B. (2000) An assessment of the published results of animal relocations. Biological Conservation, 96, 1-11.

Fontúrbel, F.E. \& Simonetti, J.A. (2011) Translocations and human-carnivore conflicts: problem solving or problem creating? Wildlife Biology, 17, 217-224.

Frank, L.G., Hemson, G., Kushnir, H. \& Packer, C. (2006) Lions, conflict and conservation in eastern and southern Africa. In Eastern and Southern African Lion Conservation Workshop, pp. 11-13. IUCN/SSC Cat Specialist Group, Johannesburg, South Africa. 
Funston, P.J. (2001) Kalahari Transfrontier Lion Project. PopulationEcology and Long-term Monitoring of a Free-ranging Population in an Arid Environment. Endangered Wildlife Trust, Modderfontein, South Africa.

Griffin, A.S., Blumstein, D.T. \& Evans, C.S. (200o) Training captive-bred or translocated animals to avoid predators. Conservation Biology, 14, 1317-1326.

Gusset, M., Swarner, M.J., Mponwane, L., Keletile, K. \& McNutt, J.W. (2009) Human-wildlife conflict in northern Botswana: livestock predation by Endangered African wild dog Lycaon pictus and other carnivores. Oryx, 43, 67-72.

Hayward, M.W., Adendorff, J., O’Brien, J., Sholto-Douglas, A., Bissett, C., Moolman, L.C. et al. (2007) The reintroduction of large carnivores to the Eastern Cape, South Africa: an assessment. Oryx, 41, 205-214.

Hofmeyr, M. \& Van Dyk, G. (1998) Cheetah introductions to two north west parks: case studies from Pilanesberg National Park and Madikwe Game reserve. In Symposium on Cheetahs as Game Ranch Animals, p. 71. South African Veterinary Association Wildlife Group, Onderstepoort, South Africa.

Houser, A., Somers, M.J. \& Boast, L.K. (2009) Home range use of free-ranging cheetah on farm and conservation land in Botswana. South African Journal of Wildlife Research, 39, 11-22.

Hunter, L.T.B. \& Skinner, J.D. (2003) Do male cheetahs Acinonyx jubatus commit infanticide? Transactions of the Royal Society of South Africa, 58, 79-82.

Hutton, J.M. \& Leader-Williams, N. (2003) Sustainable use and incentive-driven conservation: realigning human and conservation interests. Oryx, 37, 215-226.

IUCN (1998) Guidelines for Re-introductions. IUCN, Gland, Switzerland and Cambridge, UK.

IUCN/SSC (2007) Regional Conservation Strategy for the Cheetah and African Wild Dog in Southern Africa. IUCN Species Survival Commission, Gland, Switzerland.

Johnson, S., Mengersen, K., De WaAl, A., Marnewick, K., Cilliers, D., Houser, A. \& Boast, L. (2010) Modelling cheetah relocation success in southern Africa using an Iterative Bayesian Network Development Cycle. Ecological Modelling, 221, 641-651.

Kerth, G., Gusset, M., Garbely, J., König, B., Gabanapelo, T. \& Schiess-Meier, M. (2013) Genetic sexing of stock-raiding leopards: not only males to blame. Conservation Genetics Resources, 5, 1101-1105.

Klein, R. (2007) Status report for the cheetah in Botswana. Cat News, Special issue 3, 14-21.

LinnelL, J.D.C. (2011) Can we separate the sinners from the scapegoats? Animal Conservation, 14, 602-603.

Linnell, J.D.C., Aanes, R. \& Swenson, J.E. (1997) Translocation of carnivores as a method for managing problem animals: a review. Biodiversity and Conservation, 6, 1245-1257.

Madden, F. (2004) Creating coexistence between humans and wildlife: global perspectives on local efforts to address humanwildlife conflict. Human Dimensions of Wildlife, 9, 247-257.

Marker, L.L. \& Dickman, A.J. (2003) Morphology, physical condition and growth of the cheetah (Acinonyx jubatus jubatus). Journal of Mammalogy, 84, 840-850.

Marker, L.L., Dickman, A.J., Mills, M.G.L., Jeo, R.M. \& MACDONALD, D.W. (2008) Spatial ecology of cheetahs on north-central Namibian farmlands. Journal of Zoology, 274, 226-238.
Marnewick, K., Hayward, M.W., Cilliers, D. \& Somers, M.J. (2009) Survival of cheetahs relocated from ranchland to fenced protected areas in South Africa. In Reintroduction of Top-order Predators, 1st edition (eds M.W. Hayward \& M.J. Somers), pp. 282306. Wiley-Blackwell, Oxford, UK

Massei, G., Quy, R.J., Gurney, J. \& Cowan, D.P. (2010) Can translocations be used to mitigate human-wildlife conflicts? Wildlife Research, 37, 428-439.

Mitchell, T. \& Thompson, L. (1994) A theory of temporal adjustments of the evaluation of events: rosy prospection and rosy retrospection. In Advances in Managerial Cognition and Organizational Information Processing (eds C. Stubbart, J. Porac \& J. Meindl), pp. 85-114. JAI press, Greenwich, USA.

Phillips, R.L., Cummings, J.L. \& Berry, J.D. (1991) Responses of breeding golden eagles to relocation. Wildlife Society Bulletin, 19, 430-434.

Purchase, G. \& Vhurumuku, G. (2005) Evaluation of a Wild-wild Translocation of Cheetah (Acinonyx jubatus) from Private Land to Matusadona National Park, Zimbabwe (1994-2005). Zambesi Society, Harare, Zimbabwe.

Purchase, G., Vhurumuku, G. \& Purchase, D. (2006) A wild to wild translocation of cheetahs from private farmland to a protected area in Zimbabwe (1994-2005). Cat News, 44, 4-7.

Sillero-Zubiri, C. \& Laurenson, K.M. (2001) Interactions between carnivores and local communities: conflict or coexistence? In Carnivore Conservation (eds J.L. Gittleman, D.W. Funk, D. W. Macdonald \& R. Wayne), pp. 282-312. Cambridge University Press, Cambridge, UK.

Somers, M.J. \& Gusset, M. (2009) The role of social behaviour in carnivore reintroductions. In Reintroduction of Top-order Predators (eds M.W. Hayward \& M.J. Somers), pp. 270-281. Wiley-Blackwell, Oxford, UK.

Treves, A. \& Karanth, K.U. (2003) Human-carnivore conflict and perspectives on carnivore management worldwide. Conservation Biology, 17, 1491-1499.

Weilenmann, M., Gusset, M., Mills, D.R., Gabanapelo, T. \& Schiess-Meier, M. (2010) Is translocation of stock-raiding leopards into a protected area with resident conspecifics an effective management tool? Wildlife Research, 37, 702-707.

Winterbach, C.W. (2008) Draft National Predator Strategy, Botswana. Department of Wildlife and National Parks, Gaborone, Botswana.

Wolf, C.M., Griffith, B., Reed, C. \& Temple, S.A. (1996) Avian and mammalian translocations: update and reanalysis of 1987 survey data. Conservation Biology, 10, 1142-1154.

Woodroffe, R., Thirgood, S. \& Rabinowitz, A. (2005) The future of coexistence: resolving human-wildlife conflicts in a changing world. In People and Wildlife: Conflict or Coexistence (eds R. Woodroffe, S. Thirgood \& A. Rabinowitz), pp. 388-405. Cambridge University Press, Cambridge, UK.

\section{Biographical sketches}

LORRAINE BOAST is interested in monitoring large carnivores. KYLE Good is interested in disease screening in carnivores. REBECCA $\mathrm{K}_{\mathrm{LEIN}}$ is interested in environmental education and community programmes for mitigating human-wildlife conflict. 